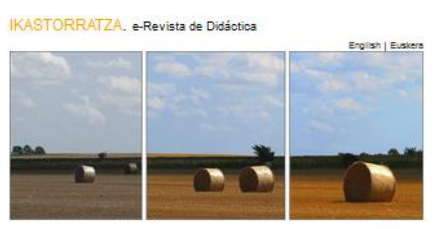

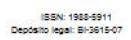

Inicio, Sobre nosotros, Publicacionesı, Participa

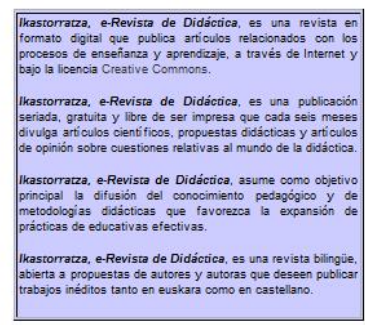

\section{IKASTORRATZA. Didaktikarako e-aldizkaria}

\author{
IKASTORRATZA. e-journal on Didactics
}

ISSN: 1988-5911 (Online) Journal homepage: http://www.ehu.eus/ikastorratza/

\title{
Una breve aproximación teórica a las interferencias culturales en el aula de español como segunda lengua en España (L2)
}

\section{IKASTORRATZA. e-Revista de Didáctica}

Claudia Pena López

claudia.pena@uva.es

To cite this article:

Pena, C. (2021). Una breve aproximación teórica a las interferencias culturales en el aula de español como segunda lengua en España (L2). IKASTORRATZA. e-Revista de Didáctica, 26, 53-72. DOI: 10.37261/26_alea/3

To link to this article:

https://doi.org/10.37261/26_alea/3

Published online: 31 March 2021 


\title{
Una breve aproximación teórica a las interferencias culturales en el aula de español como segunda lengua en España (L2)
}

\section{A brief theoretical approach to cultural interference in the Spanish classroom as a second language in Spain (L2)}

\author{
Claudia Pena López \\ Universidad de Valladolid \\ claudia.pena@uva.es
}

\section{Resumen}

Este trabajo tiene como objetivo demostrar la necesidad del estudio de la pragmática y la cultura en la enseñanza de segundas lenguas (L2) o lenguas extranjeras (LE), y más específicamente en la enseñanza del español como L2 en el contexto de la lengua y cultura españolas. Con este fin, se pretende demostrar que la competencia intercultural es clave a la hora de evitar malentendidos o conflictos en el aula de L2, donde la diversidad cultural es la norma; así como defender la necesidad de otorgar mayor importancia a la comunicación extralingüística. Para ello, se reflexiona acerca del concepto de cultura y la necesidad de "desaprender" las bases de la cultura propia para entender las normas de la nueva lengua. Por último, se reflexiona acerca del rol del profesorado de L2 como mediador intercultural y se concluye que la pragmática es fundamental para asegurar una competencia plena en cualquier L2 o LE.

Palabras clave: cultura, español, intercultural, pragmática, segunda lengua (L2).

\begin{abstract}
This study aims to prove the necessity of introducing pragmatics and culture in second and foreign language acquisition, and more precisely in teaching Spanish as a foreign language in Spain. This study tries to prove that the intercultural competence is crucial in order to prevent misunderstandings or conflicts when teaching second languages, where cultural diversity is the norm. It also highlights the necessity of conceding the importance to the extralinguistic communication in foreign languages. Therefore, it looks back on the conception of culture and the necessity of "unlearning" the basis of one's culture, in order to properly understand the rules of the new language. Finally, this study conceives the second language teacher as a mediator in intercultural teaching and concludes that pragmatics is essential to ensure a full competence in any foreign or second language.
\end{abstract}

Keywords: culture, intercultural, pragmatics, second language (L2), Spanish. 


\section{Introducción}

El objetivo de este trabajo es demostrar la importancia del aspecto pragmático de la lengua y la relevancia de la cultura en todo aprendizaje linguiístico. Por ello, nos pareció oportuno basarnos en el recorrido al que deben hacer frente todas aquellas personas adultas que, pese a sus orígenes dispares, se ven obligadas a aprender el español dentro de su contexto de habla.

El eje principal de este trabajo pretende efectuar un análisis general de las dificultades que van más allá de la lengua y que se presentan en el camino de las y los aprendices de español (en España, en el caso que nos concierne) debido a las diferentes concepciones del mundo impuestas por la cultura. El acento que aplicamos a la significancia de la pragmática nos llevará a analizar aspectos tales como los malentendidos o posibles conflictos en el aula, la comunicación no verbal y el rol de mediador intercultural que ha de ejercer el profesorado; todo ello desde una perspectiva que pretende reflexionar acerca de qué es la cultura y cuáles son sus límites.

Asimismo, nos parece importante defender un planteamiento que gira fundamentalmente alrededor de la comprensión y de la expresión oral. Esta importancia que se le otorga a la oralidad tiene su explicación en que, cuando se piensa en el español como segunda lengua $(\mathrm{L} 2)^{1}$, la idea primera es la de una lengua vehicular que dé un uso práctico a sus nuevos/as hablantes: una integración natural en la vida diaria del país que les resulte lo más similar posible a la vida que podrían llevar de estar desenvolviéndose plenamente en sus lenguas maternas.

Así pues, la finalidad sería la familiarización con los hábitos y quehaceres de los hispanohablantes ${ }^{2}$ para garantizar una asimilación de los mismos lo más veloz posible con su consecuente integración social. En esta ocasión nos centraremos en los aspectos teóricos en lo concerniente a la enseñanza del español conversacional a estudiantes adultos de español como L2. Conviene señalar que las aptitudes teóricas y los matices acerca del concepto "cultura" pueden variar en función de la escala generacional. No obstante, no conviene olvidar que, pese al peso de la cultura y a la importancia de una

\footnotetext{
${ }^{1}$ Entendemos que una Lengua Extranjera (LE) es toda lengua aprendida diferente de la materna. Una Segunda Lengua (L2), además, será aquella lengua que implique la existencia de una lengua materna, cuyo dominio será menor al de esta y cuyo uso está destinado a un contexto de habla y convivencia con la L2.

${ }^{2}$ A lo largo de este artículo, el término hispanohablante se utiliza para designar a las y los hablantes de España.
} 
buena integración del alumnado en la sociedad hispanohablante (en este caso en España), la gran particularidad de grupos de este perfil es que están constituidos por aprendices de procedencias muy dispares, por lo que las interferencias culturales y los malentendidos estarán a la orden del día, y evitar y prevenir estos últimos constituirá la labor última del profesorado, así como su gran reto.

A continuación, procederemos a exponer nuestro trabajo, comenzando por una breve contextualización acerca del vital papel de la pragmática en la enseñanza de lenguas extranjeras, seguida de una reflexión sobre la definición de la cultura y de los derivados que la acompañan, para concluir señalando la responsabilidad de la figura del profesorado en el aula pluricultural.

\section{La pragmática en la enseñanza de segundas lenguas}

La pragmática constituye un elemento fundamental en el aprendizaje de toda lengua extranjera (LE) y, sin embargo, esto no impide que su consolidación se remonte a los años 70. Esta paradoja resulta difícil de comprender si tenemos en cuenta que la pragmática explica todos aquellos componentes comunicativos que trascienden la lengua hablada. Esta área de la lingüística pretende estudiar las diferencias entre lo que se dice y lo que se quiere decir; es decir, un/una hablante puede formular un enunciado que semánticamente signifique una cosa, pero cuya interpretación pragmática no tenga nada que ver con los significantes (Landone: 2009).

Así pues, un/una hispanohablante dirá “¡Qué mal huele aquí! ¿No?”, lo cual podría equivaler a un "Por favor, ventila la estancia" para la persona también de habla hispana que se encontrase más cerca de la ventana. Un/una hablante más sensible pudiera interpretarlo como que tal vez al mencionar el olor se pretenda insinuar un descuido en su higiene personal o en la de otra de las personas presentes.

En un contexto de interacción natural entre dos hablantes, una exclamación y una pregunta de esta índole conducirían necesariamente a un intercambio de impresiones y elucubraciones acerca de la procedencia o causa de ese olor desagradable. Del mismo modo que cuando alguien halaga la indumentaria de otra persona con un "¡Vaya, qué zapatos más bonitos llevas!", a un/a hispanohablante le resultará de lo más natural explicar con total lujo de detalles de dónde procede dicho calzado, lo cual se acompañaría probablemente de algún comentario atenuador que aclarase el origen humilde del mismo, 
como por ejemplo "Pues son de la temporada pasada" o "No te creas que me costaron muy caros...”. Señalar hechos como estos, que pueden semejar caricaturales o hiperbólicos a ojos de ciertos lectores, es en realidad bastante acertado, puesto que si un/una hablante francés/francesa alabase los zapatos de un/a hispanohablante y este/esta le explicase que son ya viejos o que están descatalogados, el francófono/a se quedaría atónito/a al no recibir un simple y cordial "gracias” por respuesta (Barros: 2009).

Nos encontramos, lógicamente, ante detalles susceptibles de variar en función de las y los hablantes y de su espontaneidad o sociabilidad, pero que constituyen un comportamiento suficientemente característico de la sociedad española como para que convenga explicar al alumnado que se han erigido incluso como normas no escritas de cortesía para sus hablantes (Barros: 2009). Precisamente por ello, en el lado opuesto de la balanza, un español o española al que un francés o francesa le respondiese con un mero "gracias" a un cumplido, lo interpretaría como un gesto descortés y hasta brusco, un signo de malos modales. Saber discernir si un acto de habla o un gesto debe resultar ofensivo o no para el/la hablante, o si este debe ser concebido como un acto de falta o exceso de cortesía, resulta como mínimo tan elemental como conocer el vocabulario de una lengua (Bernal: 2005). Para las y los hispanohablante, cuanto más indirecta resulte una pregunta, más respetuosa y educada será a su vez. Las culturas orientales, en cambio, tienen tendencia a tratar los asuntos de manera directa, sin dar el menor de los rodeos.

La comunicación humana es de por sí un acto complejo que va mucho más allá de la interpretación de códigos lingüísticos, su uso y los gestos u otros actos que los acompañen conforman el campo de estudio de la pragmática, que vela desde no hace mucho por establecer un modo adecuado de transmitir estos complejos conocimientos al alumnado de lenguas extranjeras. A menudo, lograr que el alumnado tome consciencia de la magnitud de la pragmática y de su repercusión en la comunicación se establece como una tarea más que ardua. No obstante, su dominio se vuelve imprescindible para quienes deseen poseer un conocimiento profundo de la lengua e integrarse plenamente en la nueva sociedad de la que forma parte (Knapp y Hall: 2007).

Por este motivo pretendemos ejemplificar algunos de los casos en los que el conocimiento extralingüístico se vuelve conditio sine qua non para detentar una competencia comunicativa completa y efectiva en la lengua de expresión de las y los hablantes. Pondremos constantemente el acento sobre los conceptos de pragmática y cultura, a 
menudo empleados casi de manera equivalente, por estimar que la una ejerce una influencia constante sobre la otra y no podrían existir como tales de manera independiente (Miquel: 2004).

\section{3. ¿Qué entendemos por cultura?}

A menudo, cuando se piensa en el aprendizaje de una LE, se recurre a la cultura como un medio, pero se descuida el hecho de que debe constituir ante todo un fin (Miquel y Sans: 2004). Por este motivo no resulta extraño que en un aula de español como lengua extranjera, sea cual sea su público, se hable de gastronomía, de tradiciones, de diferencias entre Comunidades Autónomas, o de los distintos países de habla hispana. Sin embargo, es frecuente que estos datos se traten de manera superflua y rara vez se profundicen y se trasciendan los significantes que sobrepasan la anécdota de lo cultural.

Como ya se ha señalado en el anterior apartado, la enseñanza de la pragmática resulta fundamental para formar hablantes competentes en una LE. Este aspecto se vuelve todavía más imprescindible para las y los estudiantes de español como L2, puesto que se trata de personas que estarán obligadas a convivir de manera prolongada en un ámbito de inmersión lingüística total, con todo lo que ello conlleva. El contacto constante con una civilización y una lengua que les son ajenas puede conducir a situaciones incómodas o desagradables que fácilmente podrían evitarse si previamente se hubiese contado con una contextualización cultural adecuada. No obstante, para efectuar dicha contextualización conviene establecer los parámetros de qué abarca el término cultura y qué no. Y, en este caso, nos surge un interrogante: ¿qué entendemos por cultura?

El diccionario virtual de la Real Academia Española (RAE) define el término cultura, en su tercera acepción, y de acuerdo con su actualización más reciente, como el "conjunto de modos de vida y costumbres, conocimientos y grado de desarrollo científico, industrial, en una época, grupo social, etc." De acuerdo con esta definición, parece evidente que la repercusión de la lengua en la cultura es (de manera caricaturizada) un dato anecdótico.

La cultura está presente en la vida de sus hablantes de manera tan natural que pasa desapercibida. Los hábitos rutinarios (como despedidas, formas de sentarse a la mesa o reacciones ante un regalo) varían considerablemente de una cultura a otra; sin embargo, por tratarse de hábitos adquiridos como "normales", las y los hablantes no reflexionan 
antes de actuar, lo que puede conducir a situaciones desagradables e incómodas, y hasta a grandes malentendidos. Como señala Galindo Merino (2006): "Existen reglas comunicativas específicas a cada cultura". Esto significa que hay ciertos rasgos comunicativos que no solo escapan a los conocimientos lingüísticos, sino que también lo hacen al sentido común. De este modo, si bien para un español o española sería descortés saludar a un compañero o compañera de trabajo con un "Hola, ¿todo bien?" y no recibir más que un "sí" por respuesta, para un francés o francesa esta interacción sería de lo más normal.

Por este motivo es de vital importancia introducir en el aula de L2 la competencia pragmática e implicarse en la enseñanza de la cultura como algo que va mucho más allá del arte, de la historia o del folclore. Escandell (1996) lo deja muy claro:

\footnotetext{
Es fácil observar cómo cada cultura ha ido especializando un conjunto propio de fórmulas más o menos fijas para interactuar en ciertas situaciones preestablecidas y asegurar, así, una interacción fluida y sin malentendidos: es el caso, por ejemplo, de los saludos, despedidas, felicitaciones..., etc. El conocimiento y el uso adecuado de las fórmulas propias de cada comunidad constituyen, pues, uno de los objetivos centrales del aprendizaje de una lengua.
}

Como precisa Escandell, el conocimiento y correcto uso de las fórmulas de cada comunidad de hablantes constituyen un pilar fundamental en el aprendizaje de una lengua. En el caso que nos concierne, este factor resulta aún más crucial si cabe, puesto que estaríamos hablando de hablantes de L2, que han de construir su vida en torno a la lengua y la cultura españolas, por la cual se verán influidos/as en su día a día de manera duradera. Por este motivo, el buen conocimiento de la pragmática y de las reglas no escritas de la comunicación no verbal se presenta como la única vía para evitar malentendidos e interferencias indeseables en la comunicación entre hablantes de L2 y hablantes nativos/as. De nuevo Galindo Merino (2006) plantea una reflexión al respecto, puesto que nos comenta que para los nativos y nativas existen actitudes tan hondamente asimiladas que su incumplimiento puede conducir a un severo juicio de las actuaciones del o la hablante de L2:

\footnotetext{
Las normas socioculturales que rigen nuestras actuaciones lingüísticas en lengua nativa nos aportan una óptica especial desde la cual juzgamos no solo a quienes comparten el idioma, sino también al resto, sin que seamos conscientes de ello. Esto hace que apliquemos las pautas de conducta verbal que conocemos a las situaciones aparentemente similares, aunque se desarrollen en una lengua distinta. Sabemos que, con frecuencia, este tipo de transferencia puede ser causa
} 
de errores pragmáticos.

Para evitar errores pragmáticos, es fundamental conocer la lengua más allá de su forma y evitar el traslado literal o exacto de las palabras de una lengua a otra. Esto no se puede conseguir sin el conocimiento profundo y formado de la cultura de las y los hablantes nativos. Suele decirse que un ser humano posee tantas visiones del mundo como lenguas conoce, lo cual implica de manera necesaria que cada una de sus concepciones del mundo irá estrechamente vinculada a las concepciones arraigadas en la cultura de la lengua que hablen.

Estos datos son además más complejos de lo que pudiera parecer, puesto que una lengua no va necesariamente vinculada a una única cultura, lo cual resulta especialmente evidente en el ámbito que nos concierne, puesto que la lengua española es una lengua muy rica en matices lingüísticos, los cuales derivan de su gran diversidad cultural. Esta diversidad puede profundizarse aún más si se analiza un territorio más reducido y nos concentramos exclusivamente en el territorio español. Las Comunidades Autónomas de nuestro país se presentan como un ejemplo perfecto de hasta qué punto la cultura influye en la lengua y de cómo, pese a la disparidad, existe un nexo capaz de permitir las "generalizaciones". Un buen ejemplo de ello sería la polisemia léxica de la lengua española (Zhang, 2019).

Más allá de las fronteras de nuestro país y de nuestra lengua, cabe señalar que existen también vínculos comunes a otros países, que permiten precisamente que la comunicación intercultural sea posible. En palabras de Lejarcegui Gutiérrez (2005):

\footnotetext{
Cada comunidad construye un sistema cultural que le es propio a través del cual deben ser interpretadas las diversas manifestaciones pero que puede presentar similitudes con otros sistemas culturales. Son estas convergencias culturales las que permiten la comunicación entre los pueblos que de otro modo serían absolutamente impermeables unos a otros. Las divergencias constituyen la especificidad y la originalidad de cada pueblo. Para poder comprender una sociedad y sus miembros hay que estar en posición de identificar sus sistemas de clasificación y de percibir sus leyes de funcionamiento, sus regularidades y su lógica social. Iniciar al alumnado en la percepción de otra cultura y por otra parte a comunicar en otra cultura es ponerlos en contacto con los filtros culturales a través de los cuales toda información será percibida y asimilada, filtros que remiten a procesos cognitivos generalmente inconscientes.
}

Precisamente por lo que comenta Lejarcegui, se ha considerado que sería interesante poder tratar las interferencias culturales en el aula de español como L2. Reflexionar 
acerca de propuestas didácticas que traten la enseñanza de los conocimientos culturales en el aula se presenta como un reto tan atractivo como enriquecedor. Otero Brabo Cruz (2005) comenta que: "Sin el conocimiento de una lengua/cultura, no se logra provocar la impresión que se desea en su interlocutor/a".

Este argumento, extrapolable a todas las lenguas, es fundamental a la hora de comprender por qué insistimos en poner el acento sobre la influencia cultural en el aprendizaje de una L2. Un/una hablante que desee poseer una competencia completa en su L2 necesitará un conocimiento profundo del dominio cultural, y en consecuencia, pragmático.

Asimismo, al referirnos a la competencia pragmática de una lengua, cabe mencionar la variable laboral de la persona que desarrolla su competencia comunicativa en L2. Así pues, es de suponer que un/una hablante de español como L2 deseará en un momento dado introducirse en el mercado laboral. Esta inserción sería viable pese a carecer de un conocimiento total de la lengua; sin embargo, no lo sería tanto de no poseerse una competencia plena en los ámbitos pragmático y cultural. Otero Brabo Cruz (2005) insiste en un aspecto que ya hemos mencionado con anterioridad y recalca que el aprendizaje de una lengua nos permite, como decíamos, acceder a distintas perspectivas del mundo en que vivimos. Así pues, para ella, el estudio o aprendizaje de una lengua no debiera limitarse al deseo de integrar el mercado laboral ni de incrementar las fronteras académicas; sino que debería más bien ir dirigido a una contemplación de sí mismo/a y de las diferentes facetas que se logran desarrollar en función de en qué lengua o cultura se haga:

El aprendizaje de una LE va más allá de la inserción en el mercado de trabajo, llevándolo a comprender lo gratificante que es aprender una lengua extranjera aprendiendo también nuevas culturas, además de descubrir nuevas maneras de observar el mundo y de observarse a sí mismo.

En este sentido, se presentaría la cultura no solamente como una entidad estrechamente vinculada al correcto aprendizaje de una LE o L2, sino como una vía para el autoconocimiento y la expansión de las barreras interpersonales gracias al amplio abanico de perspectivas que propicia la familiarización con múltiples culturas.

Nos parece importante tomar consciencia de la repercusión del ámbito cultural en el estudio y enseñanza del español como L2. El peso de la cultura provoca que la lengua no se quede al margen y presente modificaciones o adaptaciones que atestigüen esta 
correlación. La relevancia de la cultura en el día a día tanto del profesorado como de las y los hablantes ha sido la razón que nos ha llevado a abordar el siguiente aspecto, que nos permitirá constatar que el impacto cultural ha calado hasta lo más hondo de la lengua.

\section{La influencia de la cultura en la lengua}

Una de las particularidades que se pretende poner de manifiesto es el rol primordial de la cultura en el aprendizaje de cualquier LE o L2. Si bien es cierto que las excepciones son tan numerosas como lo son quienes aprenden o hablan de forma nativa una lengua, también lo es que existe una serie de características comunes a cada hablante. De acuerdo con ello, es inimaginable ubicar a un/una hablante fuera de un ámbito cultural (Álvarez: 2010).

La cultura no solo determina qué uso ha de hacerse de la lengua en función del contexto en que se emplee, sino que fija también una serie de estructuras y fórmulas que solo se conciben dentro de esa cultura específica. Un buen ejemplo de lo que comentamos serían el vocabulario y la riqueza léxica. De acuerdo con esto, no nos sorprendemos si en finés cuentan con cientos de palabras para matizar el tono del color blanco, o en gallego otras tantas para referirse a la lluvia. Estaríamos aquí ante dos casos en que el entorno repercute en la cultura, puesto que se trata también de dos elementos que no se pueden desvincular. Esto explica de manera muy gráfica por qué un/una hablante de Finlandia puede llegar a sentirse limitado en español cuando quiere describir un tono de blanco, puesto que dentro de su sentir cultural la definición de este tono de blanco sería más perfecta si tuviese a su disposición los mismos medios que le proporciona su lengua materna. A menudo se adoptan palabras de otros idiomas precisamente porque logran transmitir más que las de la propia lengua. En español, por ejemplo, contaríamos con el vocablo gallego "morriña" para referirnos a un sentimiento que no podríamos describir con tanta precisión de no adoptar un término procedente de otra lengua, puesto que la "nostalgia" existe, pero no implica en absoluto los mismos matices.

Detalles como estos denotan una influencia de la cultura en la lengua en un sentido positivo, puesto que la enriquecen; no obstante, la influencia pudiera ser negativa si el alumnado trasladase una estructura o pensamiento lingüístico a una LE/L2 que no tuviese las mismas connotaciones en su lengua materna. Por este motivo, la enseñanza de pragmática y cultura en el aula de español como LE/L2 resulta primordial; más aún si 
cabe en el aula de L2, pues se presupone que el alumnado hará un uso del idioma completamente enfocado a la inserción en una sociedad que a priori le resulta ajena. Domínguez Vázquez (2001) trata este tema de manera muy acertada puesto que nos recuerda que:

No podemos perder de vista en ningún momento que el individuo transfiere no solo las formas y los significados de su propia lengua y cultura sino también la distribución de estas formas y sus significados a la lengua y cultura extranjera. Pero este fenómeno no se produce solamente activamente al intentar hablar el idioma y desenvolverse en la nueva cultura, sino también, pasivamente, al tratar de comprender la lengua y la cultura según la practican sus nativos.

Esta cita condensa a la perfección lo que comentamos acerca del peligro de trasladar directamente las estructuras de una lengua a otra. La correcta interpretación de ciertos errores dependerá directamente de la empatía cultural de cada interlocutor/a, así como de su capacidad para replantearse que quizás la comprensión no ha sido la correcta debido a algún tipo de interferencia cultural. Lo más peligroso sería que el alumnado de español como L2 aplicase a las y los hablantes nativos las formas y significados de su lengua y cultura a la hora de interpretar los mensajes. Esto podría hacerle creer, en el más extremo de los casos, que toda una sociedad le profesa un rechazo que escapa a su comprensión.

El hecho de que puedan darse malentendidos tan notorios en el aprendizaje y la convivencia con unas lengua y cultura extranjeras debiera resultar suficiente para asumir el relevante papel de la pragmática en nuestra vida diaria. De hecho, como indica muy acertadamente Escandell (1996), los hábitos pragmáticos mal adquiridos son mucho más difíciles de corregir que los meramente lingüísticos, y su interferencia en la interacción, más perjudicial:

\footnotetext{
El grado de fijación de los supuestos culturales que rigen la interacción es altísimo, de manera que los hábitos pragmáticos son mucho más difíciles de corregir que los puramente gramaticales: se ha observado, por ejemplo, que los nietos y bisnietos de emigrantes que se establecieron en un nuevo país, que ya no hablan la lengua de sus mayores, sin embargo, mantienen todas las inercias conversacionales de su cultura de origen.
}

Los matices son múltiples cuando se trata de aprender o enseñar una L2, las particularidades que hay que tener en cuenta son incontables y a ellas se suman las del propio alumnado. Suele decirse que cada persona es un mundo, y este mundo no podría ser menos complejo si se le añade además la necesidad de aprehender otro mundo 
totalmente distinto como el que implica aprender una L2. En este sentido, el mismo alumnado no estará igual de receptivo si está contento o deprimido, ni si se encuentra en un ambiente tranquilo y distendido o en un entorno demasiado bullicioso. Como comenta Domínguez Vázquez (2001):

Las diferencias culturales serán clave para la explicación de numerosos fenómenos lingüísticos. El proceso de la interferencia en el aprendizaje de lenguas extranjeras no se debe solo a diferencias culturales entre comunidades lingüísticas, ni únicamente a las diferencias tipológicas de las lenguas, sino también y además a las características individuales de cada aprendiz y su situación y contexto, así se pueden considerar aspectos psicológicos y físicos como causantes de interferencia, como la excitación, miedo, cansancio, etc.

Por otra parte, de acuerdo con la idea defendida por Lejarcegui (2005), es importante introducir desde un primer momento la enseñanza de la cultura en el aula de español como L2, ya que todo individuo posee ideas estereotipadas de las y los hablantes de otras lenguas, lo cual no necesariamente tendrá una influencia positiva en el aprendizaje de estas lenguas, sino más bien todo lo contrario:

Nos interesa también el estudio del estereotipo porque las representaciones que el alumnado tiene de la lengua que aprende son anteriores al aprendizaje de la lengua misma. Sin embargo, hay aspectos, como en el caso de la gestualidad, que crea código igual al de su lengua materna y "calca" sobre los códigos de su propia cultura. Debido a este hecho y a este apriorismo cultural, pretender enseñar la civilización una vez que el alumnado se desenvuelva en la lengua que aprende no hace más que mantener una separación entre lengua y cultura que, en realidad, no forman más que una entidad. A lo largo del curso, el alumnado tenderá, a través del filtro del estereotipo, a proyectar o a confirmar lo que sabía previamente de la cultura que aprende.

Conforme a las palabras de Lejarcegui, no se debería permitir que una "base ideológica" previa influyese en el aprendizaje de una L2. Esta, además, estaría al alcance de cualquier individuo, al margen de que se dedicase o no a aprender la lengua en cuestión. Cuando un/una hablante decide, por los motivos que sea, lanzarse de lleno al estudio de una nueva lengua, lo más deseable sería que lo hiciese de la mano de un profesorado capaz de abrirle las puertas a la totalidad de la realidad del mundo en que se introduce. En otras palabras, es imposible entender un código como el lingüístico de manera adecuada si se desconoce el vasto mundo que lo rodea; lengua y cultura son dos partes de un todo que resulta incomprensible si no se aprenden a partir de una tabula rasa desprovista de cualquier tipo de estereotipo o idea preconcebida. 


\section{Malentendidos e interferencias culturales}

Los conflictos que pueden surgir de manera natural entre dos hablantes de distintos orígenes se multiplican al encontrarnos en un aula pluricultural, como sucede notablemente en las aulas de español como L2. No solamente se trata de conflictos lingüísticos, sino que estos van mucho más allá y suelen ser el reflejo del desconocimiento de la pragmática, a la que se le atribuyen desde los errores culturales hasta los errores de comunicación no verbal, tema que trataremos en el siguiente apartado.

Los malentendidos por interferencia cultural podrían evitarse si se diese una asimilación correcta de la pragmática. Escandell (1996) defiende sin cesar la importancia del tratamiento pragmático a la hora de aprender una nueva lengua, puesto que representa un factor condicionante a la hora de hacer uso de la L2:

Sin duda ninguna, uno de los aspectos en los que la necesidad de adoptar un enfoque pragmático se hace más patente es el que se refiere a la manera en que la cultura y la organización social nativa de quienes aprenden una lengua extranjera determinan y condicionan el uso de la lengua objeto de aprendizaje.

Las palabras de la lingüista dejan bastante claro que entender la cultura y el comportamiento de una sociedad es imprescindible para quienes deseen o necesiten hacer un uso correcto de una lengua diferente de su lengua materna. Ambos factores se recogerían en el estudio de la pragmática. Previamente abordábamos el tema de la influencia de la cultura sobre la lengua, así como explicamos que los errores gramaticales quedan relegados a un segundo plano cuando entran en juego los errores pragmáticos. Escandell (1993) recalca este dato del siguiente modo:

Efectivamente, los factores socio-culturales son, claramente, ajenos a la lengua misma; sin embargo, su influencia sobre el comportamiento verbal es extraordinaria, y es la que da lugar a la mayoría de los fenómenos que suelen agruparse bajo la denominación de interferencia pragmática. Las interferencias pragmáticas no siempre resultan fáciles de detectar o de prever; y, sin embargo, sus efectos son, en la mayoría de los casos, mucho más graves que los producidos por las interferencias gramaticales.

Escandell insiste, pues, en que los factores socioculturales son efectivamente ajenos a la propia lengua. Anteriormente se insistía sobre la variabilidad de aplicaciones en función del individuo y de su estado particular, así como sobre el hecho de que cada lengua concedía la llave de un mundo de perspectivas totalmente diferentes de las otras, por lo 
que un individuo tendría tantas concepciones del mundo como lenguas dominase. Precisamente dentro de esta idea, Escandell pretende explicar que es precisamente el/la hablante el/la responsable de construirse esta misma perspectiva en función de su propio bagaje vital:

Cada individuo construye un conjunto particular de supuestos y de representaciones del mundo de acuerdo con su propia experiencia vital: pero significa también que los miembros de una misma cultura y de una misma sociedad comparten un amplio conjunto de supuestos y de conceptualizaciones del mundo y de las relaciones interpersonales, y que ese conjunto está determinado precisamente por su pertenencia a una cultura específica.

Lo recogido en este párrafo se corresponde perfectamente con la idea tratada de que, pese a las especificidades de cada individuo, es posible establecer una categoría más general que englobe el común de la cultura de una nación. En otras palabras: si se puede hablar de una cultura específica a un país, región, lengua, etc., esto demuestra indiscutiblemente que pueden extraerse vínculos comunes a sus habitantes o hablantes. La posibilidad de crear una categoría común determina que también sea posible la enseñanza de cultura y pragmática. Por este motivo, es fundamental tomar consciencia de que la introducción de ambas es fundamental en el aula para que el alumnado alcance una competencia comunicativa completa en la que no surjan malentendidos inconcebibles con los/las hablantes nativos/as.

Brandimonte (2006) resume de la siguiente manera todos los aspectos que han de conocerse para estar en posesión de una competencia comunicativa completa:

\footnotetext{
La competencia comunicativa implica no sólo conocer el código lingüístico, sino también saber qué hay que decir y a quién dirigirse, y cómo hay que decirlo de forma apropiada en cualquier situación dada. Esta competencia se relaciona con el conocimiento social y cultural que los hablantes poseen y que les permite utilizar e interpretar las formas lingüísticas (...) incluye tanto el conocimiento como las expectativas acerca de quién puede hablar en determinados contextos y quién no puede hacerlo, cuándo hay que hablar y cuándo hay que callar, a quién se puede dirigir la palabra, cómo se puede hablar con personas de un estatus y rol diferentes al propio, cuáles son los comportamientos no verbales adecuados a diferentes contextos, cuáles las rutinas para tomar la palabra en una conversación, cómo se puede solicitar información y cómo se la puede proporcionar, cómo se puede preguntar, cómo ofrecer ayuda o colaboración y cómo declinar la oferta, cómo se pueden dar órdenes, imponer disciplina, etc. En suma, todo aquello que implica el uso lingüístico en un contexto social determinado.
}

Bradimonte hace referencia a un detalle tan nimio como los turnos de palabra. En la 
cultura española interrumpir a su interlocutor/a implica a menudo estar de acuerdo con sus argumentos o empatizar con la historia que le están refiriendo. Lo que en una cultura suele interpretarse como algo positivo, en otras puede no serlo en absoluto; de acuerdo con esto un interlocutor o interlocutora de Inglaterra podría ofenderse si se cortase su turno de palabra, como si su discurso no fuese suficientemente importante para su receptor/a. Evitar confusiones como esta es muy sencillo si se aplican los parámetros de la pragmática en el aula y saber que la interrupción de una persona hispanófona de España puede llegar a ser halagadora ayudaría probablemente al alumnado anglosajón a encontrar la motivación que necesitan para mejorar su nivel.

Lo cierto es que confusiones de este tipo pueden llegar a herir la sensibilidad de quienes aprenden una nueva lengua, sobre todo si lo hacen con el fin de introducirse en la sociedad que la habla, llegando a desmotivar e incluso desmoralizar al individuo, que podría sentir rechazo hacia su nueva cultura. Evitar este tipo de interferencia negativa en el aprendizaje de la L2 es uno de los objetivos fundamentales de la docencia. Esta es perfectamente consciente de las dificultades que afronta el alumnado, y así quiso plasmarlo Corros Mazón (2006):

\footnotetext{
Muchas veces, tal y como algunos estudiantes norteamericanos nos comentaron, los malentendidos culturales dejan una profunda huella en el que los sufre, provocando situaciones de estrés, agudizando el choque cultural e influyendo negativamente en el proceso de aprendizaje de la lengua española.
}

Nelson Mandela aseguraba que al dirigirse a una persona en una lengua que comprendiese se llegaría a su cerebro, pero al hacerlo en su lengua materna se accedía a su corazón. Corros Mazón (2006), en una especie de paráfrasis de esta idea, eleva la cultura al nivel de la lengua, llegando a sobrepasarla, y asegura: "Los errores culturales y de competencia pragmática tocan la fibra sensible del interlocutor nativo, mientras que los errores lingüísticos suelen despertar el afán cooperativo".

De acuerdo con esto, no es descabellado afirmar que en la cultura española se presenta una fuerte tendencia a ayudar a un interlocutor/a extranjero/a que se vea limitado/a por sus conocimientos lingüísticos. Este afán cooperativo se vería no obstante condicionado si se diesen errores de índole pragmática, ya que se ha comentado que se trata de aspectos asimilados y aprehendidos acerca de los que rara vez se planteará preguntas un/una hablante nativo/a; de ahí la relevancia de tratar los aspectos pragmáticos en el aula. 
Lejarcegui (2005) confecciona una magnífica recapitulación sobre cómo se producen los malentendidos culturales entre interlocutores/as de distintas culturas, así como describe el proceso de interpretación efectuado por un/una hablante que desconoce la pragmática de su interlocutor/a y viceversa. Al mismo tiempo, defiende la enseñanza/aprendizaje de la pragmática y proporciona una genial contextualización de cara al siguiente apartado acerca de la comunicación no verbal:

\footnotetext{
En la interacción cultural entran en juego mecanismos particulares que pueden generar malentendidos en la comunicación. Es decir, cada cual percibe al otro a través de sus propias marcas de referencia, valores y hábitos, a su vez determinados por su pertenencia socio-cultural y su historia personal. Trabajar sobre los malentendidos producidos por los códigos gestuales de dos culturas, en nuestro caso la española y la francesa, podría ser una vía de aproximación a la problemática relacionada con la comunicación no verbal en ambas culturas y que se traduce de forma explícita en la enseñanza/aprendizaje del francés como lengua extranjera. A través de los gestos se expresa, de forma inconsciente y al mismo tiempo unos signos sociales y culturales y una personalidad. El malentendido gestual interviene cuando uno de los interlocutores interpreta de forma errónea los gestos del otro a través de sus propias categorías de clasificación, es decir, percibe e interpreta a través de su propio código. Aprender a objetivar los gestos, a tomar conciencia de la polisemia gestual en una cultura diferente se vuelve objetivo en la enseñanza/aprendizaje de una lengua extranjera.
}

\section{La comunicación no verbal (CNV)}

La comunicación no verbal (CNV) ejemplifica de manera excelente algunos de los aspectos referidos con anterioridad. Cuando recalcamos la relevancia de la pragmática a la hora de interpretar correctamente un contexto comunicativo, resumíamos que el aprendizaje de un idioma no iba exclusivamente ligado a la lengua, sino también a la pragmática, y que esta última abarcaba mucho más que lo estrictamente cultural. La CNV constituye un proceso comunicativo en el que la emisión y recepción de mensajes se efectúa sin palabras de por medio; en su lugar, se emplean indicios, gestos o signos.

La correcta interpretación de la pragmática implica también la interpretación de aquel lenguaje que acompaña al acto de habla. En este sentido, la CNV merece especial atención cuando la L2 a la que el alumnado hace frente es tan expresiva como la española, en la que el lenguaje gestual constituye una parte fundamental. Contrariamente a otras culturas, más comedidas en el uso, por ejemplo, de la gestualidad, la cultura española y el carácter de las españolas y los españoles propician que a menudo se den malentendidos con 
hablantes de otros países, que no logran interpretar de manera adecuada la actitud de su interlocutor. Como precisa Escandell (1996): “Cada cultura hace también elecciones diferentes respecto de lo que se entiende como 'amenazante' para el otro. Por ejemplo, las diferencias en la conceptualización del desacuerdo con el interlocutor dan como resultado una selección diferente de estrategias".

Un ejemplo bastante frecuente sería hablar de la manera de asentir con la cabeza. Mientras que en España se puede estar diciendo que "no" al mover la cabeza de derecha a izquierda, en Bulgaria esto sería interpretado como un "sí". Lo que para las y los hispanohablantes constituiría una negación, en Bulgaria lo emplean como una manera de afirmar. Un gesto tan simple y rutinario podría dar lugar a una importante confusión que, en función del contexto, podría incluso ser bastante grave.

Otra de las características que se citaban con respecto al lenguaje corporal en España era la tendencia a acompañar el discurso con abundantes gestos. Esta costumbre parecería estar todavía más expandida en Italia, donde (de manera caricaturizada) no lograrían comunicarse si no pudiesen recurrir a la CNV. Brandimonte (2006) describe magníficamente en qué consiste esta forma de CNV y precisa que se trata de un código que permite transmitir emociones y completar el sentido de las palabras:

\footnotetext{
El lenguaje corporal forma parte, sin duda, del patrimonio genético de los italianos, siendo uno de los aspectos más evidentes que salta a la vista y hasta tal punto que muchos afirman que un italiano sin brazos no podría comunicarse. Este código cinético, compuesto por miradas, muecas, expresiones del rostro, posturas, acompaña y completa el sentido de las palabras en base a una serie de normas y convenciones compartidas y está íntimamente relacionado con la cultura de cada país. Los pueblos mediterráneos, incluyendo a los africanos, con las debidas diferencias, suelen manifestar sus emociones a través de una kinésica más contundente con respecto a los pueblos del norte de Europa.
}

A grandes rasgos puede decirse que la comunicación humana requiere un complemento no verbal para alcanzar su máxima efectividad. Este artículo refuerza constantemente la idea de que es necesario dominar los aspectos extralingüísticos de toda L2 con el fin de conseguir una inmersión e integración total en el país de destino. La CNV no podía, como es lógico, quedar excluida de este estudio y merece que se le preste especial atención, puesto que la kinética forma parte de esos hábitos rutinarios efectuados por inercia, cuya asimilación es tan natural que el/la hablante nativo/a ni siquiera considera que pueda variar de una lengua a otra. 
Corros Mazón (2006) lo explica mediante una reflexión que sintetiza lo que hemos pretendido esbozar en este breve apartado: "Una adecuada fluidez y competencia cultural, ha de basarse, en gran medida, en una adecuada fluidez en los elementos de comunicación no verbal y en su integración con los componentes pragmáticos lingüísticos y paralingüísticos".

\section{Conclusiones: cómo ejercer de mediador en un aula pluricultural}

A la hora de ejercer como mediador en un aula pluricultural, el profesorado podrá optar entre varios métodos o estrategias que le permitan evolucionar con su alumnado en un ambiente distendido y de igualdad en el que no haya cabida para la intolerancia. Esto no siempre resulta sencillo, sobre todo cuando se pretende introducir temas sensibles (como pueden serlo la política, la religión o el género) sin que estos trastoquen el buen clima de la clase. En cualquier caso, la opción más aconsejable siempre será aquella que permita que el profesorado alcance la máxima empatía posible del alumnado con el mundo cultural español.

En el apartado anterior se señalaba que actos rutinarios tan simples como los saludos pueden suponer un antes y un después en la actividad comunicativa del alumnado, puesto que se trata de rituales tan automatizados que se suelen dar por sentados, lo cual impide la reflexión acerca de si en la nueva lengua estos deberían ser modificados o no.

Es de vital importancia centrarse en los valores socioculturales (susceptibles de variar de una cultura a otra, por muy cercanas que estas puedan estar entre sí), que pueden y deben aplicarse a aprendices de español como L2 de prácticamente cualquier procedencia. El análisis y la comparación con sus culturas de origen se presenta como un excelente apoyo para el alumnado, cuya empatía puede aumentar gracias a la puesta en perspectiva de detalles que les pasarían desapercibidos de no tratarse en el aula junto a un profesorado nativo de su L2.

Con el fin de lograr tratar todos aquellos aspectos pragmáticos necesarios para el correcto aprendizaje de una nueva lengua, y más todavía para su correcta asimilación, parece fundamental que las y los aprendices sientan que progresan en una lengua real que les ayude a afrontar situaciones reales. Por esta razón, resulta vital que el profesorado les presente materiales cuya aplicación sea directa, para que de este modo el alumnado pueda ser consciente de inmediato de la aplicación práctica de los conocimientos que adquiere. 
La enseñanza de la pragmática constituye probablemente una de las disciplinas de más compleja aplicación en el aula, y paradójicamente representa a su vez una de las más importantes. Debido a ello, el profesorado concentra una responsabilidad más que considerable, puesto que es el único capaz de tender al alumnado el saber que necesita para comprender realmente el funcionamiento de la sociedad en la que ha de integrarse. Un adecuado conocimiento de la pragmática y de los usos y costumbres de una sociedad impedirán que se generen situaciones desagradables en el día a día del alumnado y servirán como prevención de posibles conflictos.

Como ya hemos abordado con anterioridad, la aplicación de la pragmática en la enseñanza de idiomas es de gran relevancia, puesto que conviene destacar la fuerte impronta que la cultura ejerce sobre el lenguaje. Esto no es debido sino a que la cultura se ve constantemente reflejada en la lengua y en los hábitos de sus hablantes. De acuerdo con ello, una lengua y cultura tan ricas como la española varía considerablemente en función de quién y dónde la hable. Si la cultura, y por ende la pragmática, no tuviesen una repercusión sobre el lenguaje, el español no gozaría muy probablemente de la gran riqueza que le conocemos en nuestros días.

Por este motivo, es fundamental que el profesorado sepa cómo transmitir este aspecto abstracto del aprendizaje de una L2 a su alumnado. Del mismo modo que la lengua española refleja incontables aspectos pragmáticos, también las lenguas maternas del alumnado de L2 reproducen a su vez determinados aspectos pragmáticos. Ello genera que se representen de manera concreta (a través del lenguaje oral o escrito) aquellos conceptos o ideas que en realidad son abstractos (fruto de la pragmática), los cuales son susceptibles de engendrar malentendidos o malestar en el aula.

En definitiva, podríamos resumir concluyendo que la figura del profesorado de español como L2 hace frente a una labor nada sencilla. En primera instancia, se encuentra en la tesitura de deber transmitir unos conocimientos poco concretos y a menudo vinculados con sentimientos o percepciones innatos, debido a haber sido adquiridos y asimilados de manera inconsciente a causa de la pertenencia a un determinado grupo sociocultural. En segunda instancia, ha de lidiar con un conjunto de aprendices de orígenes identitarios muy dispares, lo que no solo dificultará la partida desde un punto de comparación cultural común, sino que además deberá alcanzar la empatía cultural logrando armonizar puntos de vista y percepciones del mundo ya en un principio altamente divergentes entre sí. 


\section{Bibliografía}

Álvarez, S. (2010): "La relevancia del enfoque intercultural en el aula de lengua extranjera", Revista Nebrija de Lingüística Aplicada, Madrid, pp. 40-58.

Barros, M.J. (2009): La didáctica del español actual. La integración del saber cultural en el aula de ELE: cuestiones de cortesía. Granada. Universidad de Granada.

Bernal, M. (2005): "La alo-repetición como estrategia de cortesía y descortesía en la conversación conflictiva". Actas del II coloquio internacional del programa EDICE. Costa Rica y Estocolmo. EDICE.

Brandimonte , G. (2006): “Competencia pragmática e interferencias culturales en la enseñanza del español a estudiantes italianos”, La competencia pragmática y la enseñanza del español como lengua extranjera, Oviedo, Servicio de Publicaciones de la Universidad de Oviedo, pp. 196-207.

Corros Mazón, F.J. (2006): “Aspectos pragmáticos, sociolingüísticos e interferencias culturales en la enseñanza de ELE en Estados Unidos", La competencia pragmática y la enseñanza del español como lengua extranjera, Oviedo, Servicio de Publicaciones de la Universidad de Oviedo, pp. 213-221.

Domínguez Vázquez, M.J. (2001): "En torno al concepto de interferencia”, Círculo de lingüística aplicada a la comunicación, Madrid, Universidad Complutense de Madrid.

Escandell Vidal, M.V. (1993): Introducción a la pragmática, Barcelona/Madrid, Antrophos/UNED.

Escandell Vidal, M.V. (1996), "Los fenómenos de interferencia pragmática”, Didáctica del español como lengua extranjera, Cuadernos del Tiempo libre, Colección Expolingua, Madrid, Editorial Actilibre.

Galindo Merino, M.M. (2006): “La transferencia pragmática en el aprendizaje de ELE”, La competencia pragmática y la enseñanza del español como lengua extranjera, Oviedo, Servicio de Publicaciones de la Universidad de Oviedo, pp.289-297. 
Knapp, M. Y Hall, J. (2007): Nonverbal Communication in Human Interaction. Boston, Wadsworth.

Landone, E. (2009): "Reflexiones sobre la cortesía verbal en la enseñanza/aprendizaje del ELE”, Revista electrónica Marcoele, Madrid.

Lejarcegui Gutiérrez, M.C. (2004): “Interferencias culturales en la comunicación no verbal en lengua extranjera", Simposio "Didáctica de Lenguas y Culturas”, A Coruña, Servizo de Publicacións da Universidade da Coruña, pp. 201-206.

Miquel, L. (2004): “La subcompetencia sociocultural”, Vademécum para la formación de profesores. Enseñar español como segunda lengua (L2)/ lengua extranjera (LE), Madrid, SGEL.

Miquel, L. y Sans, N. (2004): "El componente cultural: un ingrediente más en las clases de lengua", RedELE, revista electrónica de didáctica ELE. Consultado el 05/08/2020. Disponible en http://hdl.handle.net/11162/72261.

Otero Brabo Cruz, M.L. (2006): “Competencia pragmática e interferencias culturales en la enseñanza de ELE para alumnos brasileños”, La competencia pragmática y la enseñanza del español como lengua extranjera, Oviedo, Servicio de Publicaciones de la Universidad de Oviedo, pp. 501-506.

Zang, N. (2019): "La polisemia léxica en la adquisición del vocabulario (ELE), Madrid, Universidad Complutense de Madrid. Tesis doctoral consultada el 03/08/2020. Disponible en: https://eprints.ucm.es/51060/1/T40836.pdf.

Zarate, G. (1986): Enseigner une culture étrangère, Paris, Hachette. 